\title{
Two-Year Follow-Up Analysis of Telaprevir-Based Antiviral Triple Therapy for HCV Recurrence in Genotype 1 Infected Liver Graft Recipients as a First Step towards Modern HCV Therapy
}

\author{
Fritz Klein, ${ }^{1}$ Ruth Neuhaus, ${ }^{1}$ Dennis Eurich, ${ }^{1}$ Jörg Hofmann, ${ }^{2}$ Sandra Bayraktar, ${ }^{1}$ \\ Johann Pratschke, ${ }^{1}$ and Marcus Bahra ${ }^{1}$ \\ ${ }^{1}$ Department of General, Visceral and Transplantation Surgery, Charité Universitätsmedizin Berlin, Campus Virchow, \\ Augustenburger Platz 1, 13353 Berlin, Germany \\ ${ }^{2}$ Institute of Medical Virology, Helmut-Ruska-Haus and Labor Berlin Charité-Vivantes GmbH, Charité Universitätsmedizin Berlin, \\ Augustenburger Platz 1, 13353 Berlin, Germany
}

Correspondence should be addressed to Fritz Klein; fritz.klein@charite.de

Received 30 November 2015; Accepted 8 March 2016

Academic Editor: Piero Luigi Almasio

Copyright (C) 2016 Fritz Klein et al. This is an open access article distributed under the Creative Commons Attribution License, which permits unrestricted use, distribution, and reproduction in any medium, provided the original work is properly cited.

\begin{abstract}
Objective. The introduction of protease inhibitors telaprevir and boceprevir in 2011 had extended the antiviral treatment options especially in genotype 1 infected hepatitis $C$ relapsers and nonresponders to interferon/ribavirin therapy. The aim of this study was to analyze the long-term treatment efficiency of telaprevir-based triple therapy for patients with hepatitis $\mathrm{C}$ reinfection after orthotopic liver transplantation. Patients and Methods. We included 12 patients with histologically confirmed graft fibrosis due to hepatitis $\mathrm{C}$ reinfection. The treatment duration was scheduled as 12 weeks of telaprevir-based antiviral triple therapy followed by 36 weeks of dual therapy with pegylated interferon/ribavirin. The patients were followed up for two years after the end of triple therapy. Results. Of the 12 patients, 6 (50\%) completed the full 48 weeks of antiviral treatment. An end of treatment response and a sustained virological response 52 weeks after the end of the antiviral treatment course were achieved in 8/12 (67\%) and 7/12 (58\%) patients, respectively. Conclusion. Telaprevir-based triple therapy was shown to be a long-term effective but complex treatment option for individual patients with hepatitis $\mathrm{C}$ graft. With the recent improvements in hepatitis $\mathrm{C}$ therapy options telaprevir may not be recommended as a standard therapy for this indication anymore.
\end{abstract}

\section{Introduction}

Hepatitis C Virus (HCV) recurrence after orthotopic liver transplantation (OLT) is the major cause of graft failure and death in HCV recipients [1]. Graft reinfection with accelerated fibrosis deposition occurs in all patients with detectable HCV ribonucleic acid (HCV RNA) at the time of transplantation, and $30 \%$ of these patients will develop graft cirrhosis within 5 years after OLT, with a mortality risk directly related to $\mathrm{HCV}$ recurrence of $15 \%[2,3]$. In addition to high $\mathrm{HCV}$ RNA levels in the early post-OLT period, factors such as HCV genotypes 1 and 4 as well as an older donor age, graft steatosis, the degree of human leukocyte antigen (HLA) matching, and the IL28B genotype of the donor and recipient have been identified as negative predictive factors for HCV recurrence
$[4,5]$. Obtaining a sustained virological response (SVR) by successful antiviral therapy can distinctly improve the graft and overall patient survival $[6,7]$. Until 2011, the standard antiviral therapy regimen consisted of a dual therapy of pegylated interferon (PegIFN) and ribavirin (RBV). In addition to a poor tolerance, especially in transplanted patients, overall SVR was only achieved in one-third of HCV-positive recipients $(-30 \%$ GT1, $-50 \%$ GT5) $[8,9]$. Therefore, establishing more efficient therapy regimens for patients with severe HCV recurrence remains essential. The introduction of the novel NS3/4 protease inhibitors (PI) boceprevir (BOC) and telaprevir (TVR) in 2011 had fundamentally changed the treatment options for HCV patients. Several clinical studies demonstrated that the addition of BOC or TVR to standard dual therapy in immunocompetent patients led to promising SVR 
rates even in patients who failed to achieve an SVR during previous treatment with PegIFN/RBV [10-12]. However, this first success of triple therapy was accompanied by a distinct increase of treatment-related serious adverse effects (SAE), such as manifest anemia, thrombocytopenia, neutropenia, bacterial infections, and decompensation of liver cirrhosis with a potentially life-threatening clinical course [13]. As an additional concern, PIs are metabolized via the cytochrome P450 (CYP) enzyme system and are substrates and inhibitors of the CYP 3A4/5 enzyme, as well as of the efflux pump Pglycoprotein (P-gp), and may therefore cause severe drugdrug interactions (DDIs) with a wide range of approved medications, including calcineurin inhibitors (CNIs) [14]. Therefore, the clinical application of PIs in the treatment of $\mathrm{HCV}$ recurrence after OLT is extremely challenging. Pharmacokinetic studies demonstrated that TVR exposure increased cyclosporine and tacrolimus levels 4.6- and 70-fold, respectively [15]. Thus, an intensified monitoring of CNI levels during TVR therapy is required to achieve a balance between toxicity due to insufficient $\mathrm{CNI}$ dose reduction and rejection due to disproportionate CNI dose reduction. Several studies have demonstrated the feasibility of combining PIs together with CNIs until today with reported SVR rates of $20 \%$ to $50 \%$ even in formerly considered hard-to-treat patients [16-19]. The recent rapid improvement in HCV therapy such as the introduction of new directly acting antivirals (DAA) and the possibility of IFN-free regimes has however led to a therapeutic hold in the clinical application of first generation PIs [20]. Due to these rapid developments in HCV treatment options clinical and academic research has of course also focused on the feasibility, management guidelines, and effectiveness of the novel anti-HCV agents. Reports of long-term results of first generation PI's treatment thus remain scarce. The aim of our study therefore was to report our results of the one-year follow-up after TVR/PegIFN/RBV triple therapy in combination with cyclosporine immunosuppression in GT1infected relapsers and previous nonresponders after OLT.

\section{Patients and Methods}

2.1. Study Design. A retrospective analysis of 12 genotype 1 infected liver graft recipients with recurrent $\mathrm{HCV}$ who underwent TVR-based antiviral triple therapy between March 1, 2012, and July 31, 2013, at the Department of General, Visceral and Transplantation Surgery at Charité University Hospitals, Berlin, Campus Virchow, was performed. All patients included in this study had confirmed $\mathrm{HCV}$ recurrence with detectable $\mathrm{HCV}$ RNA in the PCR analysis and biopsy-proven graft fibrosis according to the Desmet and Scheuer classification (0, absent; 1 , mild without septa; 2, moderate with few septa; 3, numerous septa without cirrhosis; and 4, cirrhosis) [21]. The indication to perform TVR-based antiviral therapy was based on sufficient renal function (glomerular filtration rate $\geq 60 \mathrm{~mL} / \mathrm{min}$ according to the Cockcroft-Gault formula) and red blood cell count (hemoglobin levels $\geq 10 \mathrm{~g} / \mathrm{dL}$ ), as well as on adequate patient compliance. TVR treatment was not considered in patients with allograft cirrhosis, renal insufficiency, or general contraindications to IFN therapy. This study was performed in accordance with the Declaration of Helsinki and its amendments and approved by the institutional ethic committee. All patients were extensively educated about treatment-related side effects and the increased risk of DDIs during TVR therapy. Written consent to perform TVR/ PegIFN/RBV triple therapy and consecutive PegIFN/RBV dual therapy by each patient was documented in the medical records.

2.2. Treatment Algorithm. The overall antiviral treatment duration was scheduled as 12 weeks of TVR/PegIFN/RBV triple therapy and 36 weeks of consecutive PegIFN/RBV dual therapy. Primary immunosuppression was switched from tacrolimus (TAC, Prograf ${ }^{\circledR}$ ) to cyclosporine (CyA, Sandimmun Optoral ${ }^{\circledR}$ ) prior to the beginning of treatment, and a sufficient therapeutic range for the CyA dosage was defined as a total body clearance (TBC) from 80 to $120 \mathrm{ng} / \mathrm{mL}$ depending on the time that had elapsed since OLT. In addition, all patients underwent a lead-in phase of 4 weeks of RBV (Copegus $($; Roche) at a daily dose of $600 \mathrm{mg}$ to estimate hematological and renal tolerance. Hemoglobin and serum creatinine levels were measured once a week during the lead-in phase, and the RBV dosage was eventually adjusted. Triple therapy was then begun with TVR (Incivo@; Janssen-Cilag International NV), PegIFN (Pegasys@); Roche), and RBV (Copegus $@$; Roche). TVR was given at either two daily doses of $1,125 \mathrm{mg}$ or three daily doses of $750 \mathrm{mg}$, respectively, to reach a daily dose of 2,250 mg. The CyA dosage was reduced by $50 \%$ for each patient on the day that TVR treatment started.

2.3. Safety Assessment. Visits to our outpatient department for clinical examinations and laboratory measurements of CyA levels, blood count, and clinical chemistry renal and liver parameters were scheduled three times per week during the first two weeks and then two times a week until two weeks after the end of TVR treatment. The CyA dosage was adjusted to maintain a TBC of 80 to $120 \mathrm{ng} / \mathrm{mL}$, and the RBV dosage was eventually reduced to $400 \mathrm{mg} /$ day or even $200 \mathrm{mg} /$ day, depending on the degree of cytopenia or renal function. Clinical and laboratory examinations were continued twice per month during PegIFN/RBV dual therapy. Patients were systematically screened for DDIs, as well as for treatmentrelated side effects. Erythropoietin (EPO) (Neorecormon $($; Roche) and/or packed red blood cells (PRBCs) were administered in patients with hemoglobin levels below $6.21 \mathrm{mmol} / \mathrm{L}$. Clinically manifest anemia and leukopenia were defined as hemoglobin levels below $4.97 \mathrm{mmol} / \mathrm{L}$ and leukocyte levels below $1.5 / \mathrm{nL}$, respectively. In the event of SAEs of any type, antiviral therapy was discontinued immediately.

2.4. Treatment Efficacy and Definitions. To assess the treatment efficacy, HCV RNA was measured at baseline, at weeks $4,8,12,24$, and 48 of antiviral treatment, and then at weeks 12, 30, and 52 after the end of the treatment course (Roche Cobas AmpliPrep/Roche Cobas TaqMan, Roche Diagnostics $\mathrm{GmbH}$, Mannheim, Germany; lower level of quantification $(\mathrm{LLOQ})=15 \mathrm{IU} / \mathrm{mL})$. A rapid virological response $(\mathrm{RVR})$ was defined as undetectable HCV RNA at week 4, and a complete 
TABLE 1: Patient characteristics at baseline.

\begin{tabular}{|c|c|}
\hline & $\begin{array}{l}\text { Included patient population for TVR/PegIFN/RBV } \\
\text { triple therapy }(n=12)\end{array}$ \\
\hline Age (years), mean \pm SD & $51.8 \pm 10.5$ \\
\hline Gender (male) & $7(58 \%)$ \\
\hline Body mass index $\left(\mathrm{kg} / \mathrm{m}^{2}\right)$, mean $\pm \mathrm{SD}$ & $26.4 \pm 5.3$ \\
\hline \multicolumn{2}{|l|}{ HCV genotype } \\
\hline la & $2(17 \%)$ \\
\hline $1 b$ & $10(83 \%)$ \\
\hline \multicolumn{2}{|l|}{ Previous PegIFN/RBV therapy after OLT } \\
\hline Naive & $5(42 \%)$ \\
\hline Nonresponder/relapsers & $7(58 \%)$ \\
\hline $\begin{array}{l}\text { Time between OLT and beginning TVR/PegIFN/RBV therapy } \\
\text { (months), mean } \pm \text { SD }\end{array}$ & $63.7 \pm 61.4$ \\
\hline \multicolumn{2}{|l|}{ Fibrosis grade } \\
\hline 1 & $4(33 \%)$ \\
\hline 2 & $5(42 \%)$ \\
\hline 3 & $3(25 \%)$ \\
\hline $\mathrm{HCV}$ viral $\operatorname{load}(\log 10 \mathrm{IU} / \mathrm{mL})$, mean $\pm \mathrm{SD}$ & $6.1 \pm 0.8$ \\
\hline Bilirubin $(\mu \mathrm{mol} / \mathrm{L})$, mean $\pm \mathrm{SD}$ & $23.9 \pm 13.7$ \\
\hline $\operatorname{ALT}(\mu \mathrm{kat} / \mathrm{L})$, mean $\pm \mathrm{SD}$ & $0.99 \pm 0.84$ \\
\hline Glomerular filtration rate $\left(\mathrm{mL} / \mathrm{min} / 1.73 \mathrm{~m}^{2}\right)$, mean $\pm \mathrm{SD}$ & $72.0 \pm 20.4$ \\
\hline Hemoglobin $(\mathrm{mmol} / \mathrm{L})$, mean $\pm \mathrm{SD}$ & $7.33 \pm 1.43$ \\
\hline White blood cell count $(/ \mathrm{nL})$, mean \pm SD & $4.8 \pm 1.9$ \\
\hline Platelet count $(/ \mathrm{nL})$, mean \pm SD & $222.3 \pm 105.9$ \\
\hline
\end{tabular}

RVR (cRVR) was defined as undetectable HCV RNA at weeks 4 and 12 of TVR-based antiviral therapy. An end of treatment response (ETR), an SVR 12, and SVR 52 were achieved when HCV RNA remained undetectable at the time of treatment discontinuation, 12 weeks or 52 weeks after the end of antiviral treatment, respectively. A Null Response (NR) was defined as a <2-log drop of HCV RNA at week 12, and a breakthrough (BT) was defined as the reappearance of HCV RNA at any time during treatment. A relapse was defined as undetectable HCV RNA at the end of treatment but detectable HCV RNA within 24 weeks of follow-up. Antiviral therapy was discontinued in the event of BT or if HCV RNA was not below $1000 \mathrm{IU} / \mathrm{mL}$ at week 4 of TVR therapy, in accordance with standard therapy guidelines.

\section{Results}

3.1. Patient Baseline Data. A total of 12 patients underwent TVR-based antiviral triple therapy between March 1, 2012, and July 31, 2013, at our institution. The mean patient age was 51.8 years (32-67 years), and the male-to-female ratio was seven $(58 \%)$ to five $(42 \%)$. All patients had undergone OLT due to HCV cirrhosis at our institution a mean time of 63.7 months (13-190 months) prior to beginning TVR/ PegIFN/RBV triple therapy. Ten patients had HCV genotype $1 b$, and two patients had genotype la. Seven patients had previously been treated with PegIFN/RBV. All patients had confirmed HCV RNA by PCR analysis and biopsy-proven
$\mathrm{HCV}$ recurrence, with a fibrosis grade of 1 in four patients, a grade of 2 in five patients, and a grade of 3 in three patients. No patient had histological evidence of fibrosing cholestatic hepatitis or liver cirrhosis. Liver biopsies were performed within a median time of 252.5 days (105-927 days) prior to beginning TVR therapy. All patients had compensated liver and renal functions (Table 1).

3.2. Treatment Efficacy. The mean HCV viral load at baseline was $6.1 \log 10 \mathrm{IU} / \mathrm{mL}$. Ten of the twelve patients $(83 \%)$ completed the 12 weeks of TVR/PegIFN/RBV triple therapy, and six patients (50\%) completed the intended overall treatment duration of an additional 36 weeks of consecutive PegIFN/RBV dual therapy. An RVR was achieved in 11 patients (92\%), and all 10 patients (83\%) who regularly finished TVR achieved cRVR. Forty-eight weeks after beginning TVR treatment, 8 out of 12 patients were HCV RNA negative (ETR 67\%), including three patients who had prematurely discontinued the consecutive PegIFN/RBV dual therapy after 15, 26, and 26 weeks, respectively. TVR/PegIFN/RBV triple therapy was discontinued in one patient after 4 weeks due to a persisting $\mathrm{HCV}$ viral load of 2,700 IU/mL. Three patients had an HCV relapse, which was detected 36 days after the discontinuation of 8 weeks of TVR therapy in one patient and 16 and 29 days after discontinuation of 4 and 26 weeks of PegIFN/RBV dual therapy in two other patients. One patient experienced an HCV relapse 21 days after the regular end of 


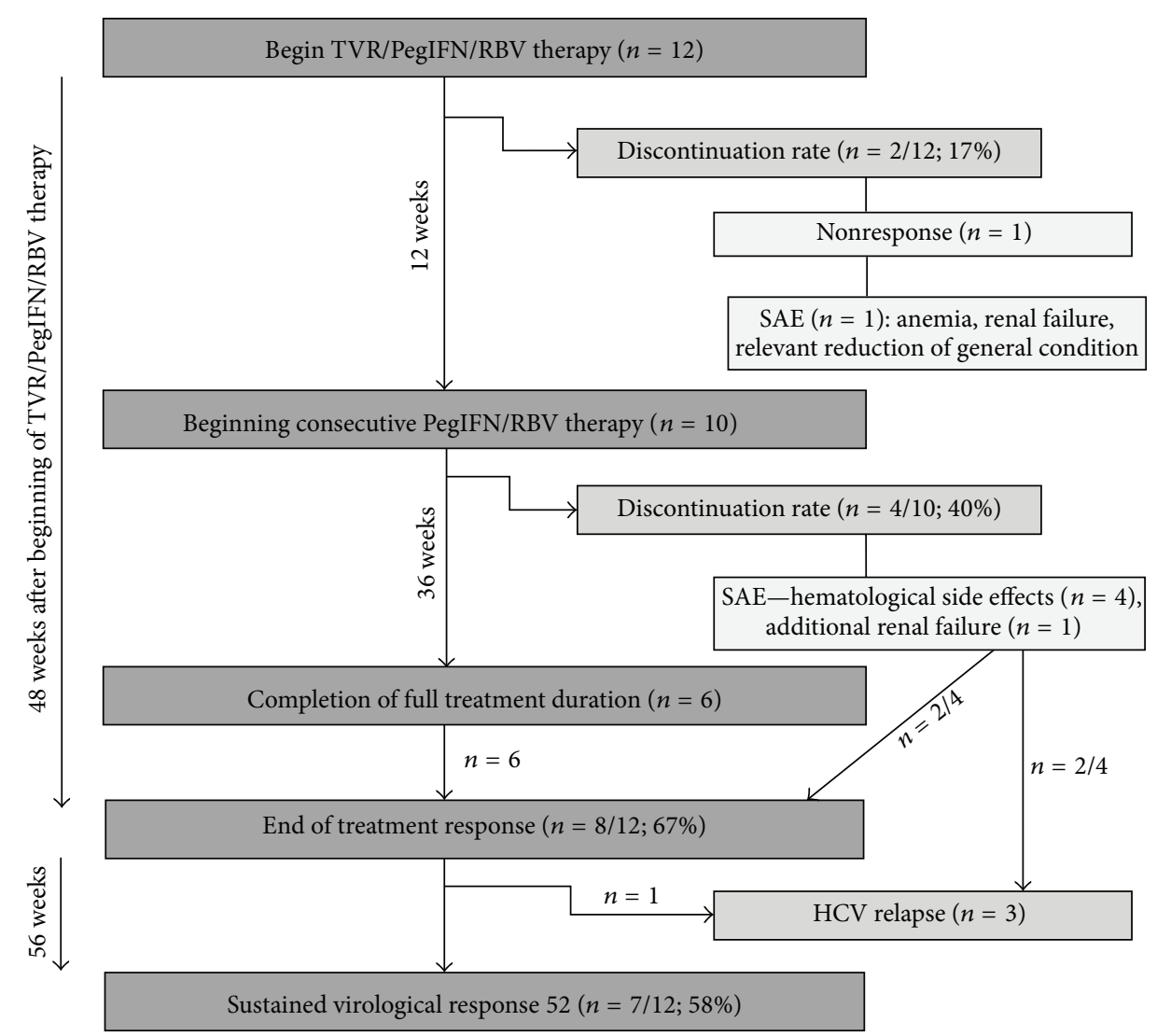

Figure 1: Treatment course and efficacy of 12 weeks of TVR/PegIFN/RBV triple therapy and 36 weeks of consecutive PegIFN/RBV dual therapy.

48 weeks of complete antiviral treatment. An SVR 12 and SVR 52 were then achieved in 7 out of the 12 patients (58\%). All 7 patients had maintained the SVR in the two-year follow-up after the end of triple therapy (Figure 1).

3.3. Management of Immunosuppression Levels during TVR Therapy. Eleven patients were switched from TAC to CyAbased immunosuppression within a mean time of 59.3 days (42-98 days) before beginning TVR therapy. One patient already had a primarily CyA-based immunosuppression. One week before beginning TVR therapy, the mean daily dose of CyA was $168.8 \mathrm{mg}(100-250 \mathrm{mg})$, with a mean TBC of $96.9 \mathrm{ng} / \mathrm{mL}$. The mean daily CyA dosage was reduced to $133.3 \mathrm{mg}$ (50-250 mg; $75 \%$ of initial daily CyA dosage), $65.5 \mathrm{mg}$ (50-150 mg; 41\%), $45.4 \mathrm{mg}$ (10-100 mg; 29\%), and $50.3 \mathrm{mg}$ (30-125 mg; 28\%) after 1 day, 7 days, 14 days, and 12 weeks, respectively, of TVR treatment. Eight weeks after the end of TVR treatment, the mean daily CyA dosage was increased fourfold, to $152.3 \mathrm{mg}$ (75-200 mg), compared with the ETR CyA dosage (Figure 2).

3.4. Treatment-Related Adverse Events. Out of the 11 patients who underwent TVR therapy for $>4$ weeks, 10 patients $(91 \%)$ suffered from treatment-related adverse effects (AEs), and one patient had to discontinue TVR therapy after 8 weeks due to severe anemia, progressive renal decompensation,

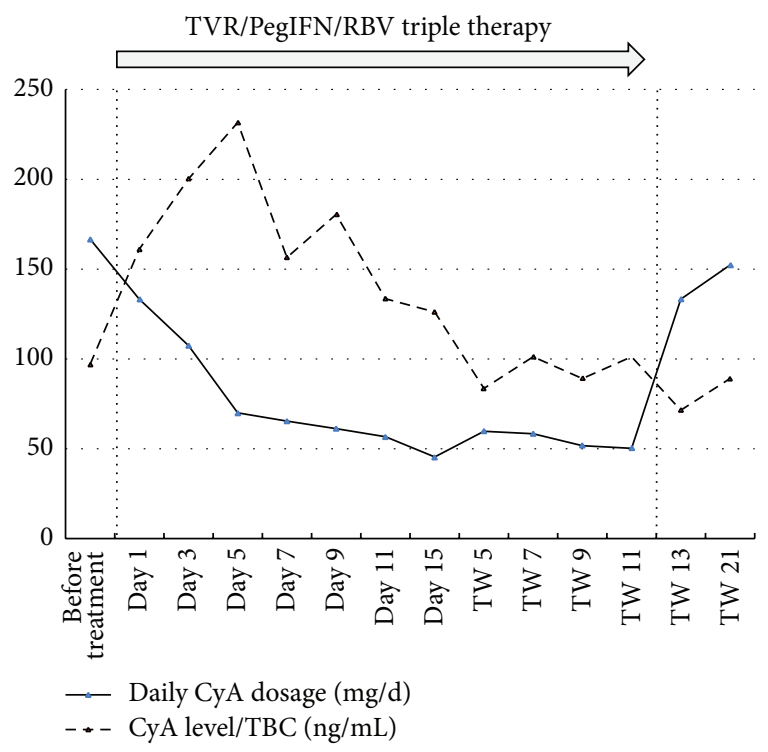

FIGURE 2: Course of immunosuppression dosage and levels during TVR/PegIFN/RBV therapy.

and relevant reduction of the patient's general condition. In the following antiviral treatment course, four patients had to discontinue PegIFN/RBV dual therapy because of 
TABLE 2: Treatment-related adverse events during TVR/PegIFN/ RBV triple therapy.

\begin{tabular}{lc}
\hline & $\begin{array}{c}\text { TVR/PegIFN/RBV triple } \\
\text { therapy }>4 \text { weeks }(n=11)^{*}\end{array}$ \\
\hline $\begin{array}{l}\text { Overall treatment-related AEs } \\
\text { during TVR/PegIFN/RBV }\end{array}$ & $10(92 \%)$ \\
$\begin{array}{l}\text { Discontinuation of } \\
\text { TVR/PegIFN/RBV due to AEs }\end{array}$ & $1(9 \%)$ \\
Anemia with hemoglobin levels \\
below 10 g/dL \\
$\quad$ EPO administration \\
$\quad$ Blood transfusion \\
$\begin{array}{l}\text { Leukopenia with a WBC count } \\
\text { below } 1.5 / \mathrm{nL}\end{array}$ \\
$\quad 5(45 \%)$ \\
GeF administration & $5(45 \%)$ \\
Infection & $5(45 \%)$ \\
Skin changes & $5(45 \%)$ \\
Anorectal pruritus & $2(18 \%)$ \\
Death & $3(27 \%)$ \\
\hline
\end{tabular}

${ }^{*}$ TVR/PegIFN/RBV triple therapy was discontinued in 1 patient after 4 weeks due to a nonresponse.

severe declines in general patient conditions combined with manifest hematological side effects (anemia and leukopenia) in each of the 4 patients and an additional renal decompensation in one patient. Two of the 6 patients who completed the full treatment duration also required an RBV dose reduction to a daily dose of $400 \mathrm{mg}$ or $200 \mathrm{mg}$, respectively. During the 12 weeks of TVR/PegIFN/RBV therapy, the mean hemoglobin level dropped from $7.4 \mathrm{mmol} / \mathrm{L}$ to $5.7 \mathrm{mmol} / \mathrm{L}$, whereas the mean WBC count dropped from $4.8 / \mathrm{nL}$ to $3.4 / \mathrm{nL}$, respectively. Five patients $(45 \%)$ developed anemia with hemoglobin levels below $6.2 \mathrm{mmol} / \mathrm{L}$ and required EPO administration during this time period. Four of these patients also received blood transfusions. Granulocyte colony-stimulating factor (GC-SF) was given to 5 patients due to a WBC below $2.5 / \mathrm{nL}$. We did not observe a decrease of GFR under TVR therapy. The median GFR decreased from $72.0 \mathrm{~mL} / \mathrm{min} / 1.73 \mathrm{~m}^{2}$ to $58.6 \mathrm{~mL} / \mathrm{min} / 1.73 \mathrm{~m}^{2}$ from the beginning to the end of the TVR/PegIFN/RBV triple therapy. In addition, 3 patients (27\%) developed infections: urinary tract infections in 2 patients and clostridium difficile diarrhea in 1 patient (9\%). Skin changes expressed by a mild rash were observed in 2 patients (18\%), and 1 patient (9\%) reported a disturbing anorectal pruritus (Table 2).

\section{Discussion}

The introduction of PIs has fundamentally changed the treatment options for patients with primary HCV and HCV recurrence after OLT even in GT1 patients with a prior nonresponse to antiviral therapy and may thus be considered as a first step towards modern HCV therapy $[10,22]$. The promising results regarding the antiviral efficacy of this rather revolutionary treatment approach have, however, been overshadowed by an increase in directly treatment-associated AEs, especially in immunocompromised patients, in whom dual therapy has already proven particularly challenging $[8$, 23-25]. At the time our study began, the two PIs TVR and BOC were approved for antiviral therapy in Europe. The therapy costs were similar, but as previous authors have noted, TVR appeared to be more "streamlined" to us in comparison to BOC [26]. In addition, Benito et al. also reported that triple therapy with TVR exhibits greater early antiviral activity than that with $\mathrm{BOC}$ which has been demonstrated to be a principal predictive factor for consecutive SVR [27, 28]. Morisco et al. recently also reported that RVR was the only independent predictive factor of antiviral response in cirrhotic patients treated by triple therapy with TVR. An even shorter therapy may thus be considered [29].

In our study, we analyzed the antiviral efficacy and safety of TVR/PegIFN/RBV triple therapy in HCV GT1-infected liver transplant recipients, a patient cohort in whom SVR rates after former standard dual therapy were rather low in comparison with genotypes 2 and 3 . In our study, we showed that despite the complexity in this setting, TVR-based triple therapy was feasible and efficient also in the long-term outcome. Eight of the 12 patients (67\%) achieved an ETR, including 2 patients who had to discontinue consecutive dual therapy prematurely due to treatment-related side effects. One patient had an HCV relapse 21 days after regularly finishing the 48-week complete antiviral treatment course. An SVR 12 and SVR 52 were then obtained in 7 of these patients (56\%). Our results are in accordance with Faisal et al., who analyzed TVR-based triple therapy for HCV recurrence after OLT in a multicenter trial and reported an ETR of 75\% and an SVR 12 of 61.5\% [19]. As an important and novel finding of our study in comparison to other reported results all patients with an SVR 12 also achieved an SVR 52. Severe PI's treatment-related AEs including death have been reported in several studies $[19,24,30,31]$. In our study, 10 of the 11 patients who underwent TVR therapy $>4$ weeks suffered from treatment-related AEs. These AEs were clinically severe enough to discontinue TVR therapy in one patient and consecutive dual therapy in 4 additional patients. The treatment discontinuation rate in our study is comparable to the results of Gallegos-Orozco in nontransplanted (high-risk) cirrhotic patients (24\%), thereby underlining the particularly difficult conditions for TVR therapy in immunocompromised patients [32]. In our study, hematological side effects were the most common treatment-related AEs. Five patients developed anemia, all of whom required EPO administration and 4 of whom required blood transfusions. Triple therapy is associated with a $20 \%$ increase in the incidence of treatment-related anemia compared with the former standard PegIFN/RBV therapy, and, according to a recent interim analysis of patients who underwent TVR therapy after OLT, 77\% of all patients require EPO administration under TVR therapy [33-35]. Additionally, 5 patients in our cohort had leukopenia and required G-CSF administration. Both anemia and leukopenia are most likely explained by the bone marrow-suppressive and nonimmune hemolytic anemia effect of RBV, which is aggravated when RBV is given in combination with TVR 
$[24,36]$. In our study, two patients also had to discontinue antiviral therapy due to severe renal decompensation, which may also be explained in the context of RBV therapy [37]. The RBV dosage may be adapted to hemoglobin and GFR levels under PI therapy with no negative effect on later SVR rates [38]. A complete cessation of $\mathrm{RBV}$, however, requires a discontinuation of TVR therapy and therefore needs to be carefully evaluated. In our study, RBV dose reduction was necessary in two of the six patients who completed the full antiviral treatment duration; one of these patients experienced HCV relapse 21 days after the regular end of the 48-week antiviral treatment course. In an attempt to assess hematological and renal tolerance before beginning TVR therapy, all patients in our study underwent a 4-week RBV lead-in phase. It appears to be reasonable to include IFN in this lead-in phase, not only to assess general therapy tolerance but also to possibly identify interferon-insensitive patients who are at risk of developing protease-resistant HCV strains during TVR therapy [39]. Patients at high risk for SAEs or virological nonresponse may thereby be identified before beginning expensive and potentially harmful TVR therapy. Another major issue for TVR therapy in transplanted patients is the complex management of immunosuppression. Dose reductions and adjustments of CNIs are required during the entire TVR treatment course due to severe DDIs. In addition to the risk of CNI toxicity, previous studies have also reported rejection episodes in 4 to $6 \%$ of patients during antiviral therapy $[40,41]$. Generally, the CyA dosage appears to be less difficult to manage because of the slighter required dose reduction compared with TAC [23]. Additionally, an additional antiviral action of CyA has been described due to the involvement of cyclophilin $\mathrm{A}$ in the viral replication of $\mathrm{HCV}$, which is underlined by the results of a meta-analysis showing that during dual therapy more patients achieved SVR with CyA than with TAC [42, 43]. All of our patients were therefore switched to CyA before beginning TVR therapy. Despite deviations in the total CyA body clearance (TBC), especially in the first days of TVR therapy, no patient developed signs of toxicity or rejection. Of course, our study is limited by the small sample size and the lack of randomization. Additionally, our patients were all well selected with regard to their general conditions and a rather less distinct fibrosis progression in comparison with studies that included rather difficult-to-treat patient populations, including patients with cirrhosis or cholestatic hepatitis [24, 44]. However, we may still conclude that TVR therapy in general as well as the concomitant management of immunosuppression may safely be performed in $\mathrm{HCV}$ GT1-infected liver graft recipients with promising SVR 52 rates. In the context of the rapid developments in $\mathrm{HCV}$ treatment options in the last years, the clinical relevance of first generation PIs has however to be considered as rather negligible nowadays. The recent introduction of novel nextgeneration antiviral agents such as sofosbuvir, daclatasvir, simeprevir, ombitasvir, paritaprevir, and dasabuvir has led to a fundamental change in the treatment perspectives of modern HCV therapy $[45,46]$. Several clinical studies have demonstrated that a combination of these new drug classes now allow interferon-free treatment regimens with a less harmful SAE spectrum, a superior antiviral efficacy, and no significant interference with immunosuppression [47-50]. The EASL guidelines for HCV treatment before and after liver transplantation have therefore recently been adapted [51]. However, the worldwide replacement of PIs by novel DAAs is until today amongst other factors limited by economic burdens. Long-term results of PI therapy efficacy as well as the emergence of resistance thus need to be continuously analyzed in order to allow an optimal and evidence-based HCV treatment also in health care systems with limited access to recent achievements of modern HCV therapy.

\section{Competing Interests}

The authors declare that they have no competing interests.

\section{Authors' Contributions}

Fritz Klein collected the data and wrote the paper. Ruth Neuhaus designed and performed the research. Dennis Eurich collected the data. Jörg Hofmann collected the data. Sandra Bayraktar collected the data. Johann Pratschke designed and performed the research. Marcus Bahra designed and performed the research. All authors have made substantial contributions to the study, including conception and design of the study, the acquisition, analysis, and interpretation of data, drafting or critical revision of the paper, and final approval of the submitted paper.

\section{References}

[1] M. Berenguer, M. Prieto, J. M. Rayón et al., "Natural history of clinically compensated hepatitis $\mathrm{C}$ virus-related graft cirrhosis after liver transplantation," Hepatology, vol. 32, no. 4, part 1, pp. 852-858, 2000.

[2] L. M. Forman, J. D. Lewis, J. A. Berlin, H. I. Feldman, and M. R. Lucey, "The association between hepatitis $\mathrm{C}$ infection and survival after orthotopic liver transplantation," Gastroenterology, vol. 122, no. 4, pp. 889-896, 2002.

[3] E. J. Gane, "The natural history of recurrent hepatitis $C$ and what influences this," Liver Transplantation, vol. 14, supplement 2, pp. S36-S44, 2008.

[4] M. Charlton, E. Seaberg, R. Wiesner et al., "Predictors of patient and graft survival following liver transplantation for hepatitis C," Hepatology, vol. 28, no. 3, pp. 823-830, 1998.

[5] M. Berenguer and D. Schuppan, "Progression of liver fibrosis in post-transplant hepatitis C: mechanisms, assessment and treatment," Journal of Hepatology, vol. 58, no. 5, pp. 1028-1041, 2013.

[6] G. Crespo, J. A. Carrión, M. Coto-Llerena et al., "Combinations of simple baseline variables accurately predict sustained virological response in patients with recurrent hepatitis $\mathrm{C}$ after liver transplantation," Journal of Gastroenterology, vol. 48, no. 6, pp. 762-769, 2013.

[7] M. Berenguer, A. Palau, V. Aguilera, J.-M. Rayón, F. S. Juan, and M. Prieto, "Clinical benefits of antiviral therapy in patients with recurrent hepatitis $\mathrm{C}$ following liver transplantation," American Journal of Transplantation, vol. 8, no. 3, pp. 679-687, 2008. 
[8] M. Berenguer, "Systematic review of the treatment of established recurrent hepatitis $\mathrm{C}$ with pegylated interferon in combination with ribavirin," Journal of Hepatology, vol. 49, no. 2, pp. 274-287, 2008.

[9] E. Xirouchakis, C. Triantos, P. Manousou et al., "Pegylatedinterferon and ribavirin in liver transplant candidates and recipients with HCV cirrhosis: systematic review and metaanalysis of prospective controlled studies," Journal of Viral Hepatitis, vol. 15, no. 10, pp. 699-709, 2008.

[10] S. Zeuzem, P. Andreone, S. Pol et al., "Telaprevir for retreatment of HCV infection," The New England Journal of Medicine, vol. 364, no. 25, pp. 2417-2428, 2011.

[11] F. Poordad, J. McCone Jr., B. R. Bacon et al., "Boceprevir for untreated chronic HCV genotype 1 infection," The New England Journal of Medicine, vol. 364, no. 13, pp. 1195-1206, 2011.

[12] H. Farnik, T. Zimmermann, E. Herrmann et al., "Telaprevir drug monitoring during antiviral therapy of hepatitis $\mathrm{C}$ graft infection after liver transplantation," Liver International, vol. 35, no. 1, pp. 176-183, 2015.

[13] J. G. McHutchison, M. P. Manns, A. J. Muir et al., "Telaprevir for previously treated chronic HCV infection," The New England Journal of Medicine, vol. 362, no. 14, pp. 1292-1303, 2010.

[14] M. Charlton and E. Seaberg, "Impact of immunosuppression and acute rejection on recurrence of hepatitis C: results of the national institute of diabetes and digestive and kidney diseases liver transplantation database," Liver Transplantation and Surgery, vol. 5, no. 4, supplement 1, pp. S107-S114, 1999.

[15] V. Garg, R. van Heeswijk, J. Eun Lee, K. Alves, P. Nadkarni, and X. Luo, "Effect of telaprevir on the pharmacokinetics of cyclosporine and tacrolimus," Hepatology, vol. 54, no. 1, pp. $20-$ 27, 2011.

[16] A. Papadopoulos-Köhn, A. Achterfeld, A. Paul et al., "Daily low-dose tacrolimus is a safe and effective immunosuppressive regimen during telaprevir-based triple therapy for hepatitis $\mathrm{C}$ virus recurrence after liver transplant," Transplantation, vol. 99, no. 4, pp. 841-847, 2015.

[17] J. R. Burton Jr., J. G. O’Leary, E. C. Verna et al., "A US multicenter study of hepatitis $\mathrm{C}$ treatment of liver transplant recipients with protease-inhibitor triple therapy," Journal of Hepatology, vol. 61, no. 3, pp. 508-514, 2014.

[18] T. Ikegami, T. Yoshizumi, M. Kato et al., "Reduced-dose telaprevir-based triple antiviral therapy for recurrent hepatitis C after living donor liver transplantation," Transplantation, vol. 98, no. 9, pp. 994-999, 2014.

[19] N. Faisal, E. M. Yoshida, M. Bilodeau et al., "Protease inhibitorbased triple therapy is highly effective for hepatitis $\mathrm{C}$ recurrence after liver transplant: a multicenter experience," Annals of Hepatology, vol. 13, no. 5, pp. 525-532, 2014.

[20] P. Y. Kwo, P. S. Mantry, E. Coakley et al., "An interferon-free antiviral regimen for HCV after liver transplantation," The New England Journal of Medicine, vol. 371, no. 25, pp. 2375-2382, 2014.

[21] V. J. Desmet, M. Gerber, J. H. Hoofnagle, M. Manns, and P. J. Scheuer, "Classification of chronic hepatitis: diagnosis, grading and staging," Hepatology, vol. 19, no. 6, pp. 1513-1520, 1994.

[22] B. R. Bacon, S. C. Gordon, E. Lawitz et al., "Boceprevir for previously treated chronic HCV genotype 1 infection," The New England Journal of Medicine, vol. 364, no. 13, pp. 1207-1217, 2011.

[23] C. R. Werner, D. P. Egetemeyr, U. M. Lauer et al., "Telaprevirbased triple therapy in liver transplant patients with hepatitis $\mathrm{C}$ virus: a 12-week pilot study providing safety and efficacy data," Liver Transplantation, vol. 18, no. 12, pp. 1464-1470, 2012.
[24] A. Coilly, B. Roche, J. Dumortier et al., "Safety and efficacy of protease inhibitors to treat hepatitis $\mathrm{C}$ after liver transplantation: a multicenter experience," Journal of Hepatology, vol. 60, no. 1, pp. 78-86, 2014.

[25] A. S. Barritt IV and M. W. Fried, "Maximizing opportunities and avoiding mistakes in triple therapy for hepatitis C virus," Gastroenterology, vol. 142, no. 6, pp. 1314-1323.el, 2012.

[26] M. L. Shiffman and R. Esteban, "Triple therapy for HCV genotype 1 infection: telaprevir or boceprevir?" Liver International, vol. 32, no. 1, pp. 54-60, 2012.

[27] J. M. Benito, C. Sánchez-Parra, I. Maida et al., “Triple combination therapy for hepatitis $\mathrm{C}$ with telaprevir exhibits greater early antiviral activity than with boceprevir," Antiviral Therapy, vol. 18, no. 5, pp. 709-715, 2013.

[28] B. Roche, M. Sebagh, M. L. Canfora et al., "Hepatitis C virus therapy in liver transplant recipients: response predictors, effect on fibrosis progression, and importance of the initial stage of fibrosis," Liver Transplantation, vol. 14, no. 12, pp. 1766-1777, 2008.

[29] F. Morisco, M. Masarone, V. Rosato et al., "Impact of telaprevir in HCV patients with cirrhosis and RVR: real-life data from Boceprevir or Telaprevir based "triple therapy" experience in southern Italy," Reviews on Recent Clinical Trials, In press.

[30] C. R. Werner, D. P. Egetemeyr, S. Nadalin et al., "Treatment of recurrent genotype 1 hepatitis $C$ post-liver transplantation: single center experience with telaprevir-based triple therapy," Zeitschrift für Gastroenterologie, vol. 52, no. 1, pp. 27-34, 2014.

[31] E. C. Verna, V. Saxena, J. R. Burton et al., "Telaprevir- and boceprevir-based triple therapy for hepatitis $\mathrm{C}$ in liver transplant recipients with advanced recurrent disease: a multicenter study," Transplantation, vol. 99, no. 8, pp. 1644-1651, 2015.

[32] J. Gallegos-Orozco, A. Chervenak, E. Carey, B. Aqel, T. Byrne, L. Hartel et al., "Liver transplant center focused experience with peginterferon $\alpha$-2a, ribavirin and telaprevir therapy in patients with genotype 1 hepatitis C cirrhosis," Hepatology, vol. 2012, p. 218A, 2012.

[33] S. Pungpapong, B. A. Aqel, L. Koning et al., "Multicenter experience using telaprevir or boceprevir with peginterferon and ribavirin to treat hepatitis $C$ genotype 1 after liver transplantation," Liver Transplantation, vol. 19, no. 7, pp. 690-700, 2013.

[34] K. E. Sherman, S. L. Flamm, N. H. Afdhal et al., "Responseguided telaprevir combination treatment for hepatitis $\mathrm{C}$ virus infection," New England Journal of Medicine, vol. 365, no. 11, pp. 1014-1024, 2011.

[35] I. M. Jacobson, J. G. McHutchison, G. Dusheiko et al., "Telaprevir for previously untreated chronic hepatitis C virus infection," The New England Journal of Medicine, vol. 364, no. 25, pp. 24052416, 2011.

[36] E. Druyts, K. Thorlund, P. Wu et al., "Efficacy and safety of pegylated interferon Alfa-2a or Alfa-2b plus ribavirin for the treatment of chronic hepatitis $\mathrm{C}$ in children and adolescents: a systematic review and meta-analysis," Clinical Infectious Diseases, vol. 56, no. 7, pp. 961-967, 2013.

[37] S. Zimner-Rapuch, N. Janus, G. Deray, and V. Launay-Vacher, "New therapies for hepatitis C: considerations in patients with renal impairment," Drugs, vol. 74, no. 12, pp. 1307-1313, 2014.

[38] F. Poordad, E. Lawitz, K. R. Reddy et al., "Effects of ribavirin dose reduction vs erythropoietin for boceprevir-related anemia in patients with chronic hepatitis $C$ virus genotype 1 infectiona randomized trial," Gastroenterology, vol. 145, no. 5, pp. 10351044.e5, 2013. 
[39] S. Susser, J. Vermehren, N. Forestier et al., "Analysis of long-term persistence of resistance mutations within the hepatitis $C$ virus NS3 protease after treatment with telaprevir or boceprevir," Journal of Clinical Virology, vol. 52, no. 4, pp. 321-327, 2011.

[40] N. Chalasani, C. Manzarbeitia, P. Ferenci et al., "Peginterferon alfa-2a for hepatitis C after liver transplantation: two randomized, controlled trials," Hepatology, vol. 41, no. 2, pp. 289-298, 2005.

[41] D. Samuel, T. Bizollon, C. Feray et al., "Interferon- $\alpha$ 2b plus ribavirin in patients with chronic hepatitis $\mathrm{C}$ after liver transplantation: a randomized study," Gastroenterology, vol. 124, no. 3, pp. 642-650, 2003.

[42] U. Chatterji, M. Bobardt, S. Selvarajah et al., "The isomerase active site of cyclophilin A is critical for hepatitis C virus replication," The Journal of Biological Chemistry, vol. 284, no. 25, pp. 16998-17005, 2009.

[43] M. Cescon, G. L. Grazi, A. Cucchetti et al., "Predictors of sustained virological response after antiviral treatment for hepatitis C recurrence following liver transplantation," Liver Transplantation, vol. 15, no. 7, pp. 782-789, 2009.

[44] C. Hézode, H. Fontaine, C. Dorival et al., "Triple therapy in treatment-experienced patients with $\mathrm{HCV}$-cirrhosis in a multicentre cohort of the French Early Access Programme (ANRS CO20-CUPIC)-NCT01514890," Journal of Hepatology, vol. 59, no. 3, pp. 434-441, 2013.

[45] P. Y. Kwo and M. B. Badshah, "New hepatitis C virus therapies: drug classes and metabolism, drug interactions relevant in the transplant settings, drug options in decompensated cirrhosis, and drug options in end-stage renal disease," Current Opinion in Organ Transplantation, vol. 20, no. 3, pp. 235-241, 2015.

[46] A. H. L. Yau and E. M. Yoshida, "Hepatitis C drugs: the end of the pegylated interferon era and the emergence of all-oral, interferon-free antiviral regimens: a concise review," Canadian Journal of Gastroenterology and Hepatology, vol. 28, no. 8, pp. 445-451, 2014.

[47] R. J. Fontana, E. A. Hughes, M. Bifano et al., "Sofosbuvir and daclatasvir combination therapy in a liver transplant recipient with severe recurrent cholestatic hepatitis C," American Journal of Transplantation, vol. 13, no. 6, pp. 1601-1605, 2013.

[48] M. Charlton, E. Gane, M. P. Manns et al., "Sofosbuvir and ribavirin for treatment of compensated recurrent hepatitis $\mathrm{C}$ virus infection after liver transplantation," Gastroenterology, vol. 148, no. 1, pp. 108-117, 2015.

[49] M. S. Sulkowski, D. F. Gardiner, M. Rodriguez-Torres et al., "Daclatasvir plus sofosbuvir for previously treated or untreated chronic HCV infection," The New England Journal of Medicine, vol. 370, no. 3, pp. 211-221, 2014.

[50] M. P. Curry, X. Forns, R. T. Chung et al., "Sofosbuvir and ribavirin prevent recurrence of hcv infection after liver transplantation: an open-label study," Gastroenterology, vol. 148, no. 1, pp. 100-107.el, 2015.

[51] European Association for Study of Liver, "EASL clinical practice guidelines: management of hepatitis $\mathrm{C}$ virus infection," Journal of Hepatology, vol. 60, no. 2, pp. 392-420, 2014. 


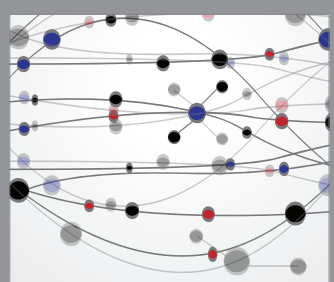

The Scientific World Journal
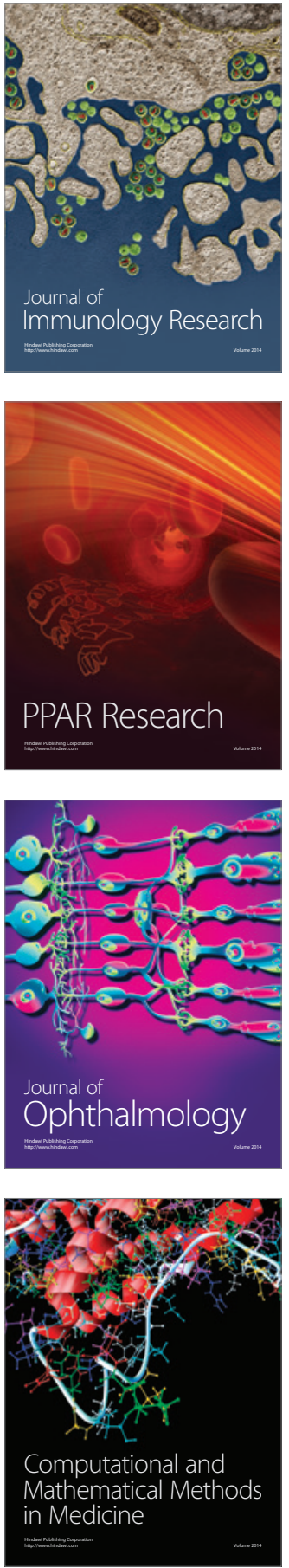

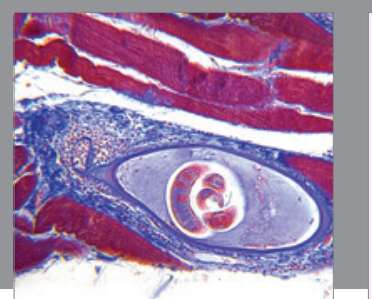

Gastroenterology Research and Practice

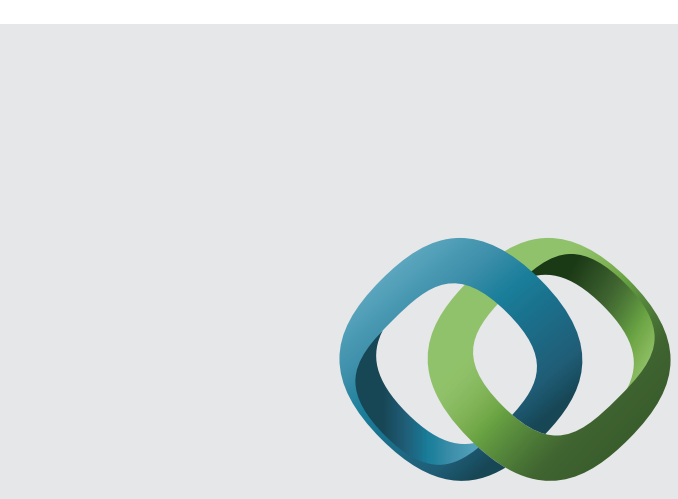

\section{Hindawi}

Submit your manuscripts at

http://www.hindawi.com
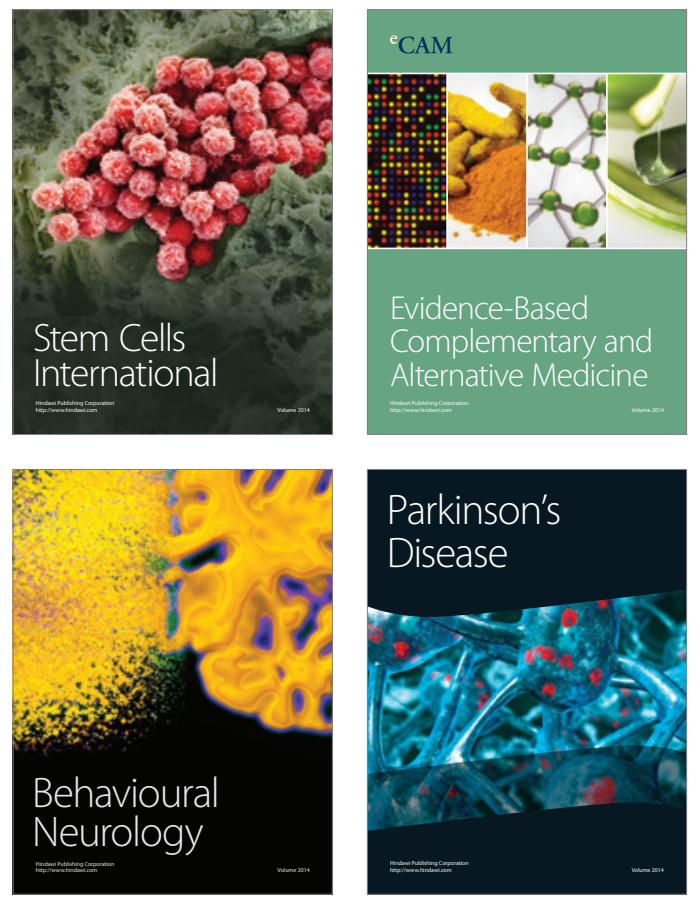
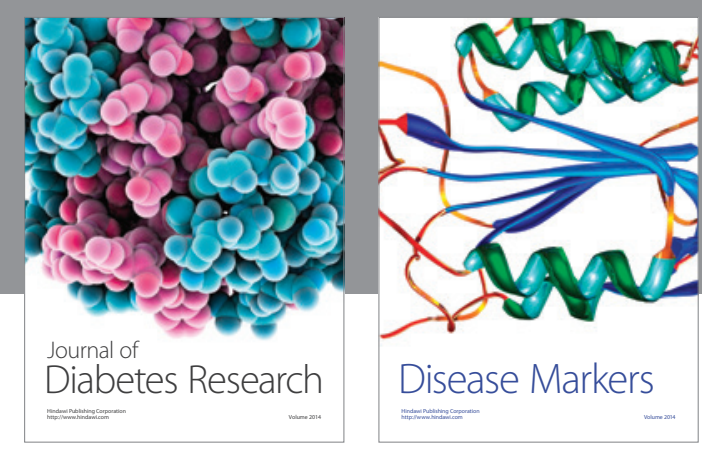

Disease Markers
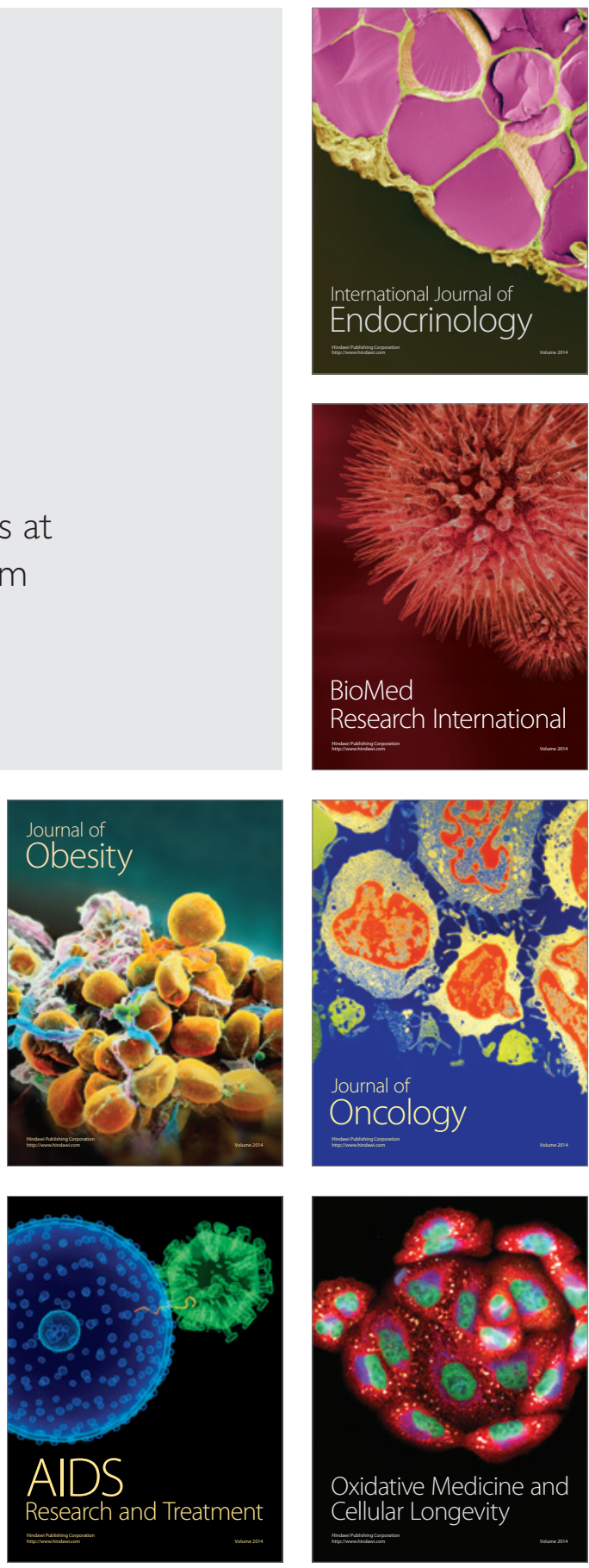